\author{
Pieter J. M. Leenen $\nabla$, \\ Marleen Melis $\nabla$, \\ Georg Kraal $\diamond$, \\ Andre T. Hoogeveen ${ }^{\bullet}$ and \\ Willem Van Ewijk ${ }^{\top}$
}

Departments of Immunology ${ }^{\nabla}$ and Cell Biology and Genetics ${ }^{\bullet}$, Erasmus University, Rotterdam and Department of Histology $\diamond$, Free University, Amsterdam

\section{The monoclonal antibody ER-BMDM1 recognizes a macrophage and dendritic cell differentiation antigen with aminopeptidase activity*}

\begin{abstract}
Here we describe the reactivity of monoclonal antibody (mAb) ER-BMDM1, directed against a $160-\mathrm{kDa}$ cell membrane-associated antigen (Ag) with aminopeptidase activity. The aminopeptidase recognized by ER-BMDM1 is present on various mouse macrophage (M $\Phi)$ and dendritic cell (DC) subpopulations as well as on microvillous epithelia. Analysis of ER-BMDM1 Ag expression in in vitro models of $\mathrm{M} \Phi$ maturation revealed that the $\mathrm{Ag}$ is expressed at increasing levels upon maturation of $\mathrm{M} \Phi$. In vivo, high level expression of the ER-BMDM1 Ag occurs after the monocytic stage of maturation, since bone marrow cells and peripheral blood monocytes are essentially ER-BMDM1 negative. Analysis of isolated-resident and elicited $M \Phi$ populations showed that ER-BMDM1 recognizes a specific subpopulation of mature $M \Phi$ : only some resident peritoneal and alveolar $M \Phi$ are ER-BMDM1 positive, whereas virtually all thioglycollateelicited peritoneal exudate $\mathrm{M} \Phi$ bind the mAb. In lymphoid organs, a subpopulation of $M \Phi$ is recognized as well as interdigitating cells (IDC) located in T cell areas. Phenotypic analysis of isolated $\mathrm{DC}$ - the in vitro equivalents of IDC - from spleen and lymph nodes confirmed that the majority of this important antigenpresenting cell population expresses the ER-BMDM1 aminopeptidase. The molecular characteristics of the ER-BMDM1 Ag suggest that it may represent the mouse homolog of human CD13.
\end{abstract}

\section{Introduction}

Mature mononuclear phagocytes comprise a very heterogeneous BM-derived cell population. The various representatives perform divergent functions, such as $\mathrm{Ag}$ presentation, phagocytosis of senescent cells, and killing of harmful microorganisms and tumor cells (reviewed in [1-3]). Most of these functions have been studied using in vitro assays on isolated populations and/or cultured cells. It remains difficult, however, to ascribe these functions to specific $M \Phi$ subpopulations located in different tissue compartments. Therefore, a detailed characterization of $M \Phi$ heterogeneity in situ is needed, using markers that are specifically indicative of particular $\mathrm{M} \Phi$ functions.

mAb directed against $\mathrm{M} \Phi \mathrm{Ag}$ greatly facilitate defining different $M \Phi$ subpopulations. For instance, ER-TR9 and MOMA-1 recognize two $M \Phi$ subpopulations in the spleen, located at the marginal zone and at the inner border of the marginal sinus, respectively $[4,5]$. Other $\mathrm{mAb}$, such as F4/80, BM8 or MOMA-2, show broader specificity, yet fail to detect particular $\mathrm{M} \Phi$ subpopulations [6-9].

In this report we define a new subpopulation of mature mouse $M \Phi$, characterized by the binding of mAb ER-

[I 10020]

\footnotetext{
* This study was supported by a research grant from the Netherlands Asthma Foundation.
}

Correspondence: Pieter J. M. Leenen, Department of Immunology, Erasmus University, P.O. Box 1738, 3000 DR Rotterdam, The Netherlands

\footnotetext{
Abbreviations: BMDM: BM-derived mononuclear phagocyte DC: Dendritic cell IDC: Interdigitating cell
}

BMDM1. A significant subpopulation of dendrocytes - i.e. Langerhans cells, veiled cells, interdigitating cells (IDC) and their in vitro equivalents, dendritic cells (DC) [10] - is also ER-BMDM1 positive. Biochemical analysis of the ER-BMDM1 Ag demonstrates that it is a $160-\mathrm{kDa}$ protein which exhibits aminopeptidase activity.

\section{Materials and methods}

\subsection{Animals, $\mathbf{m A b}$ and conjugates}

Male and female BALB/c mice were bred at our facility under clean, routine conditions and killed at 10-20 weeks of age. A female $F_{1}$ (Louvain $\times$ Lewis) rat was immunized (see below) and killed as donor of immune spleen cells.

As sources of $\mathrm{mAb}$ we used undiluted hybridoma culture supernatants, optimally diluted ascites fluid, or reconstituted purified mAb (BMA Biomedicals AG, Augst, Switzerland). In addition to the ER-BMDM1 mAb, described

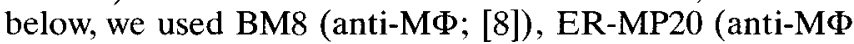
precursor; [11]), ER-TR9 (anti-M $\Phi$; [4]), F4/80 (anti-M $\Phi$; [6]), H129.19 (anti-CD4; [12]); M3/38 (anti-Mac-2 MФ Ag;

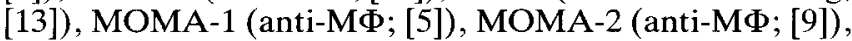
NLDC-145 (anti-IDC/DC; [14]), and RA3 6B2 (anti-B-220 $\mathrm{B}$ cell Ag; [15]).

The hybridoma producing mAb ER-BMDM1 (Erasmus University Rotterdam-BM-derived $\mathrm{M} \Phi$; $\mathrm{IgG}_{2 \mathrm{a}}$ subclass) was generated essentially as described before [11], using M $\Phi$ obtained after 7 days from M-CSF stimulated BM culture [16] as the immunogen and rat Y3-Ag1.2.3 myeloma cells as the fusion partner.

The conjugates used in this study were anti-rat Ig coupled to $\beta$-galactosidase (Radiochemical Centre, Amersham, GB or 
Zymed Laboratories, San Francisco, CA; used in ELISA), anti-rat Ig coupled to horseradish peroxidase (Dako, Copenhagen, Denmark; used in immunohistology), and FITC-coupled $F\left(a b^{\prime}\right)_{2}$ fragments of rabbit anti-rat IgG (Cappel, Malvern, PA; used in FCM).

\subsection{Target cells for hybridoma screening}

$\mathrm{mAb}$ were screened in three previously described models of MФ maturation for the recognition of maturation-stage related Ag: (a) a panel of $\mathrm{M} \Phi$ cell lines, ordered in a linear maturation sequence [17]; (b) immature and mature BMDM, isolated from macrophage (M)-CSF-stimulated BM cultures after 4 and 7 days, respectively $[11,16]$; (c) induction of maturation of the MФ precursor hybrid R0C2 using mouse post-LPS serum $+\operatorname{IFN}-\gamma[11,16]$.

In addition, ER-BMDM1 mAb was characterized by binding to several freshly isolated cell populations. BM cell suspensions were prepared in HBSS $+5 \%$ FCS by grinding femora and tibiae using a mortar. Peripheral blood nucleated cells were obtained after lysis of $E$ by a 10 -min incubation at $4^{\circ} \mathrm{C}$ in $17 \mathrm{mM}$ Tris- $\mathrm{HCl}, \mathrm{pH} 7.2$ containing $144 \mathrm{mM} \mathrm{NH}_{4} \mathrm{Cl}$. We obtained resident peritoneal and alveolar cells by lavage, using serum-free DMEM and PBS +0.6 mM EDTA, respectively. PEC were isolated at $18 \mathrm{~h}$ and 4 days after i.p. injection of $1 \mathrm{ml}$ Brewer's thioglycollate medium (Difco, Detroit, MI). These popoulations were highly enriched for polymorphonuclear cells (PMN) and $M \Phi$, respectively. DC were isolated from $\mathrm{LN}$ and spleen as described previously [18].

\subsection{ELISA, immunofluorescence labeling and FCM analysis}

Expression of ER-BMDM1 Ag by $\mathrm{M} \Phi$ cell lines and BMDM was quantified by a fluorescence micro-ELISA in Terasaki trays as described earlier [16].

Labeling procedures for immunofluorescence and FCM analysis were performed essentially as described $[11,19]$. $\mathrm{mAb}$ binding to cells was quantified by comparison of the obtained fluorescence values with those from quantitative fluorescent microbead standards (Becton Dickinson, Sunnyvale, CA). Resident peritoneal $M \Phi$ were identified in the lavage mixture on the basis of their forward- and perpendicular light-scatter characteristics. Other isolated cell populations were analyzed as total populations.

\subsection{Immunoperoxidase staining of cell suspensions and tissue sections}

ER-BMDM1 Ag expression by isolated DC was assessed at the single-cell level using an immunoperoxidase assay on cytocentrifuge preparations [20]. Immunoperoxidase staining of cryostat tissue sections was performed essentially as described by de Jong et al. [21]. A hexazotized pararosaniline solution was used for tissue fixation [21]. mAb binding was detected using either a routine diamino-benzidine (DAB) visualization of peroxidase [21], or a modified protocol involving $\mathrm{NiSO}_{4}$-supplemented DAB [22]. In the latter case sections were counterstained with nuclear fast red [22], whereas sections developed according to the regular $\mathrm{DAB}$ method were counterstained with hematoxylin.

\subsection{Biochemical characterization of the $\mathrm{Ag}$}

The molecular mass of the ER-BMDM1 Ag was determined by surface radio-iodination of cells, followed by specific immunoprecipitation and SDS-PAGE analysis, essentially as described by Pont et al. [23].

Aminopeptidase activity was demonstrated in lysates from P388D1 M $\Phi$ and small intestine cells, which were obtained by scraping. After isolation, the cells were washed twice in serum-free DMEM and lysed in 1 or $2 \mathrm{ml} 30 \mathrm{mM}$ TrisHCl, $\mathrm{pH} 8.0,1 \%$ Triton $\mathrm{X}-100,150 \mathrm{mM} \mathrm{NaCl}$ for $30 \mathrm{~min}$ on ice. The lysates were cleared by centrifugation for $15 \mathrm{~min}$ at $15000 \times \mathrm{g}$. Antigens were specifically immunoprecipitated using $\mathrm{mAb}$ coupled to anti-rat $x$ chain (MARK-1)-coated Sepharose-4B beads [23]. Prior to immunoprecipitation, the lysates were incubated for $2 \mathrm{~h}$ with plain MARK-1 beads to remove non-specifically bound proteins. The beads were washed three times in lysate buffer and incubated for $90 \mathrm{~min}$ with $0.21 \mathrm{~mm}$ leucyl- $\beta$-naphthylamide as aminopeptidase substrate in $200 \mathrm{~mm}$ phosphate buffer, pH 8.0, supplemented with $0.2 \%$ Triton $\mathrm{X}-100$. The reaction was stopped by adding $400 \mu \mathrm{l} 1 \mathrm{M} \mathrm{Na}_{2} \mathrm{CO}_{3}$ to $10 \mu \mathrm{l}$ reaction mixture. Generation of the product $\beta$-naphthylamine was monitored on a fluorometer, using an excitation wavelength of $340 \mathrm{~nm}$ and an emission wavelength of $410 \mathrm{~nm}$.

Table 1. Precipitation of aminopeptidase activity by ERBMDM1

\begin{tabular}{|c|c|c|c|}
\hline & Cells & Sample & $\mathrm{APA}^{\mathrm{a})}$ \\
\hline Exp. 1 & P388D1 & $\begin{array}{c}\text { Untreated lysate }\left(10^{5} \text { cells }\right) \\
\text { ER-BMDM1 precipitate } \\
\text { H129.19 precipitate }\end{array}$ & $\begin{array}{r}231 \\
175 \\
4\end{array}$ \\
\hline Exp. 2 & $\begin{array}{c}\text { Small } \\
\text { intestine }\end{array}$ & $\begin{array}{l}\text { Untreated lysate }\left(10^{5} \text { cells }\right) \\
\text { ER-BMDM1 precipitate } \\
\text { NLDC-145 precipitate } \\
\text { b,c) }\end{array}$ & $\begin{array}{r}153 \\
111 \\
0\end{array}$ \\
\hline Exp. 3 & P388D1 & $\begin{array}{l}\text { Untreated lysate }\left(10^{5} \text { cells }\right) \\
\text { Lysate + ER-BMDM1d) } \\
\text { Lysate + ER-MP20c,d) }\end{array}$ & $\begin{array}{l}161 \\
163 \\
164\end{array}$ \\
\hline
\end{tabular}

a) $\mathrm{APA}=$ aminopeptidase activity determined as generation of fluorescent $\beta$-naphthylamine from L-leucyl- $\beta$-naphthylamide; fluorescence is expressed in arbitrary units.

b) MARK-1-coupled Sepharose-4B beads ( $40 \mu \mathrm{l}$ wet volume), to which rat $\mathrm{mAb}$ was linked, were incubated with excess cell lysate, washed and assayed for precipitated aminopeptidase activity.

c) H129.19, NLDC-145 and ER-MP20 served as IgG $_{2 a}$ isotypematched control mAb.

d) $\mathrm{mAb}$ was added as $5 \mu \mathrm{l}$ ascites fluid (1:1 diluted in PBS) per $50 \mu \mathrm{l}$ lysate (corresponding to $10^{6}$ cells); after $30 \mathrm{~min}$ of incubation on ice, an aliquot from this mixture corresponding to $10^{5}$ cells was taken for determination of aminopeptidase activity. 


\section{Results}

\subsection{Biochemical characterization of the ER-BMDM1 Ag}

The aim of the present study was the developent of mAb against MФ which would help define functional and phenotypic heterogeneity of these cells. mAb ER-BMDM1 was found to recognize an $\mathrm{Ag}$ on various $M \Phi$ subpopulations as well as on microvillous brush borders. The latter finding prompted us to investigate a putative proteolytic function of the Ag.

Immunoprecipitation of the ER-BMDM1 Ag from WR19M.1 MФ tumor cells and subsequent SDS-PAGE showed that the $\mathrm{Ag}$ is a single polypeptide chain of approximately $160 \mathrm{kDa}$ apparent molecular mass (data not shown). Using substrates for enzymes within this size range, we investigated whether immunopurified ERBMDM1 Ag possessed any proteolytic activity. Table 1 shows that the ER-BMDM1 mAb precipitated an Ag, from both the P388D1 MФ cell line and small intestine cells, that exhibits leucine aminopeptidase activity. The mAb is, most likely, directed against an epitope distinct from the catalytic site of the enzyme, since addition of the $\mathrm{mAb}$ did not influence the observed aminopeptidase activity.

\subsection{Distribution of ER-BMDM1 aminopeptidase in situ}

\subsubsection{Lymphoid organs}

In the spleen strongly ER-BMDM1-positive cells, presumably MФ [24], surround the central arteriole (Fig. 1a). In the $T$ cell area (periarteriolar lymphocyte sheath; PALS),

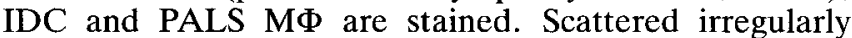
shaped cells, distinct from the marginal metallophilic $\mathbf{M} \Phi$ (Fig. 1c), are present at the inner border of the marginal sinus. Immunofluorescence double labeling (not shown) using the IDC marker NLDC-145 and the marginal metallophilic $M \Phi$ marker MOMA-1 confirmed these observations. In the splenic red pulp, two ER-BMDM1-positive cell types are present. First, patches of irregularly shaped cells are seen at the periphery of the marginal zone (Fig. 1a). In addition to ER-BMDM1 Ag, these cells express BM8, F4/80, MOMA-2, and Mac-2 Ag (de Jong and Leenen, manuscript in preparation). Based on the cellular morphology, phenotype and localization, we propose to designate these cells as "marginal red pulp $\mathrm{M} \Phi$ ". The second population of ER-BMDM1-positive cells in the red pulp is a small subpopulation of "classical" red pulp $M \Phi$, located deeper in the red pulp.

In the mesenteric LN stretched M $\Phi$, lining the inside of the LN capsule are clearly ER-BMDM1 positive (Fig. 1e). ER-BMDM1-positive IDC are easily detected in the paracortex ( $T$ cell area). In the $\mathrm{LN}$ medulla, positive $M \Phi$ are located primarily within the medullary cords. These cells are clearly distinct from the ER-TR9-positive sinus M $\Phi$ (cf. Fig. $1 \mathrm{~g}$ and $\mathrm{h}$ ).

In the thymus, cells, probably $М \Phi ~[24]$, on the inside of the thymic capsule and lining the connective tissue septa show a variable staining pattern (Fig. 2). In the cortex and corticomedullary junction, most but not all acid phosphatasepositive $M \Phi$ are recognized by ER-BMDM1. Furthermore,
mAb reactivity occurs with medullary IDC and with cells associated with cortical and medullary capillaries.

\subsubsection{Non-lymphoid organs}

Villous epithelial cells in the small intenstine are heavily labeled, especially at the brush border (Fig. 3a). The lamina propria in the villi contains only a few scattered positive cells. In contrast, in the large intestine the epithelial cells are negative, whereas the numerous $M \Phi$ in the lamina propria are clearly positive (Fig. $3 b$ ).

Strong ER-BMDM1 staining in the liver appears to be associated with the microvillous brush borders of bile capillaries (Fig. 3c). The acid phosphatase positive Kupffer cells are negative.

In the lung, there are two ER-BMDM1-positive cell types (Fig. 3d). Stretched cells surround blood vessels, and, at lower density, bronchi. Furthermore, type-II pneumocytes that express microvilli are also positive. Most alveolar MФ are negative.

\subsection{ER-BMDM1 aminopeptidase expression by isolated $\mathrm{DC}$ and $\mathrm{M \Phi}$ populations}

To confirm the notion that both $М \Phi$ and IDC in lymphoid organs are recognized by ER-BMDM1, we stained DC - the in vitro equivalents of IDC - as well as various isolated $\mathrm{M} \Phi$ populations. LN DC, identified by positive NLDC-145 staining and acid phosphatase activity located in a cytoplasmic spot, were ER-BMDM1 positive (data not shown). Virtually all LN DC are positive, whereas approximately $50 \%$ of the NLDC-145-positive splenic DC are recognized by ER-BMDM1.

BM $М \Phi$ precursors and peripheral blood monocytes express little ER-BMDM1 Ag (Fig. 4A). In contrast, approximately $60 \%$ and $30 \%$ of the $M \Phi$ in the resident peritoneal and alveolar cell populations, respectively, readily express this marker. Remarkably, virtually all thioglycollate-elicited peritoneal exudate $M \Phi$ are strongly ERBMDM1 positive. The small positive population present in the granulocytic exudate, isolated $18 \mathrm{~h}$ after thioglycollate injection, most likely represents the contribution of remaining resident peritoneal $M \Phi$. Together, these data indicate that ER-BMDM1 recognizes a particular subpopulation of $\mathrm{DC}$ and $\mathrm{M} \Phi$.

\subsection{ER-BMDM1 aminopeptidase expression in the course of MT maturation}

The observation that BM MФ precursors and peripheral blood monocytes expressed little ER-BMDM1 Ag prompted us to investigate the onset of $\mathrm{Ag}$ expression during $M \Phi$ maturation in more detail. Screening of ER$B M D M 1$ reactivity on a panel of $M \Phi$ cell lines, arrested in distinct, characterized stages of maturation [17], revealed that only cell lines with mature $M \Phi$ characteristics were recognized (Fig. 4B). In M-CSF-stimulated BM cultures, $\mathrm{mAb}$ binding was hardly detectable on nonadherent $\mathrm{M} \Phi$ precursors isolated after 4 days, whereas mature $M \Phi$ 

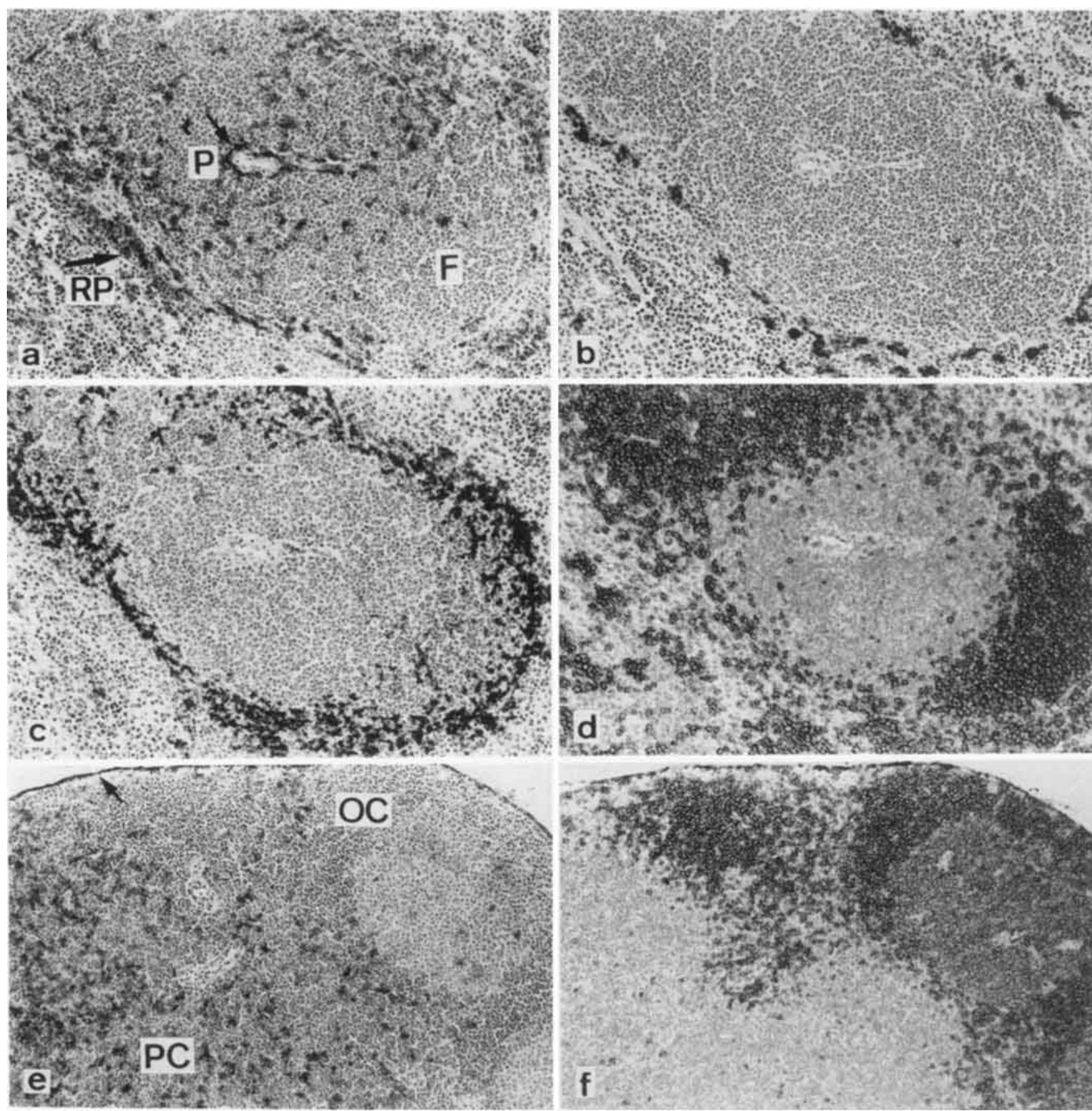

$\frac{1}{2}$

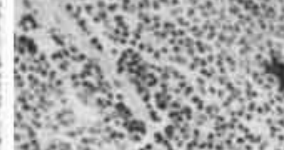

and
b

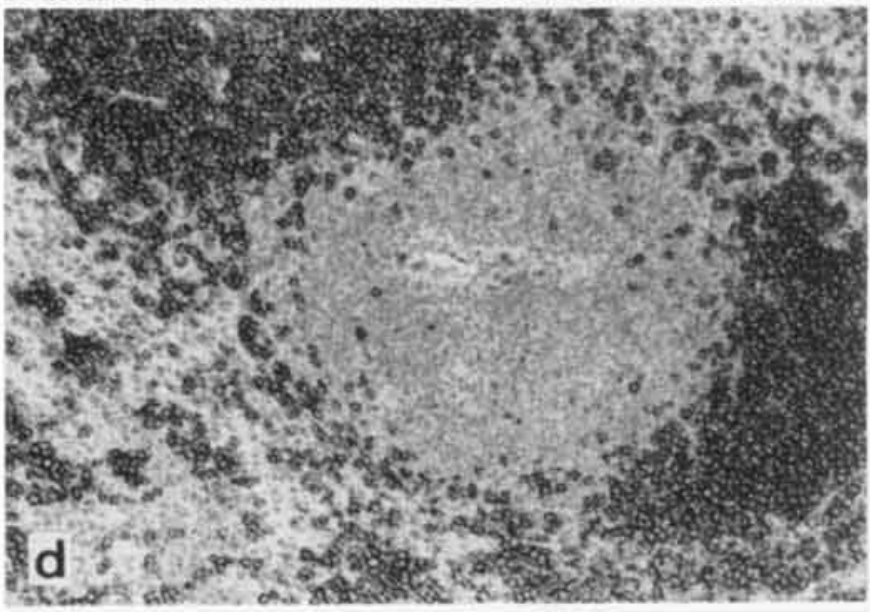
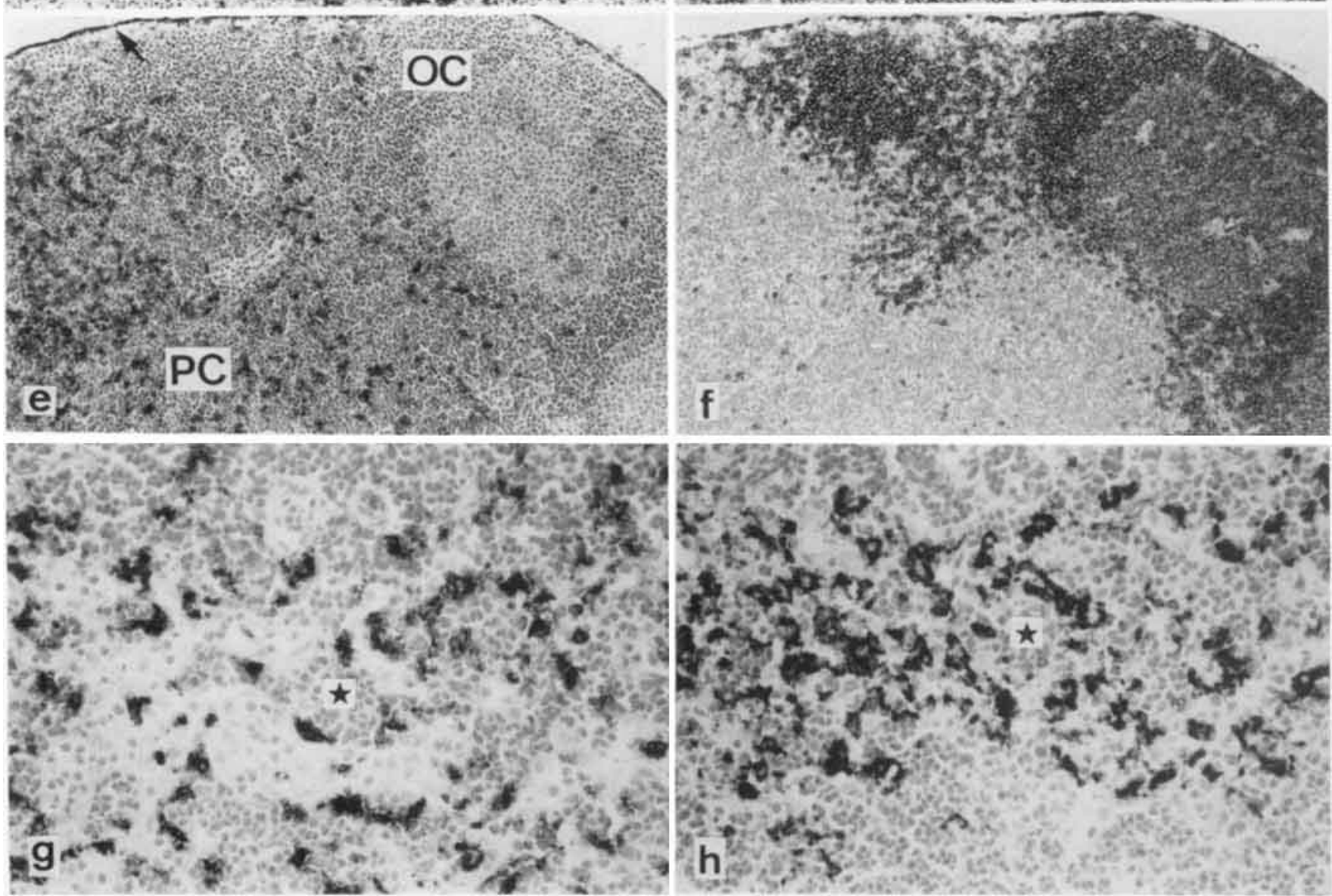


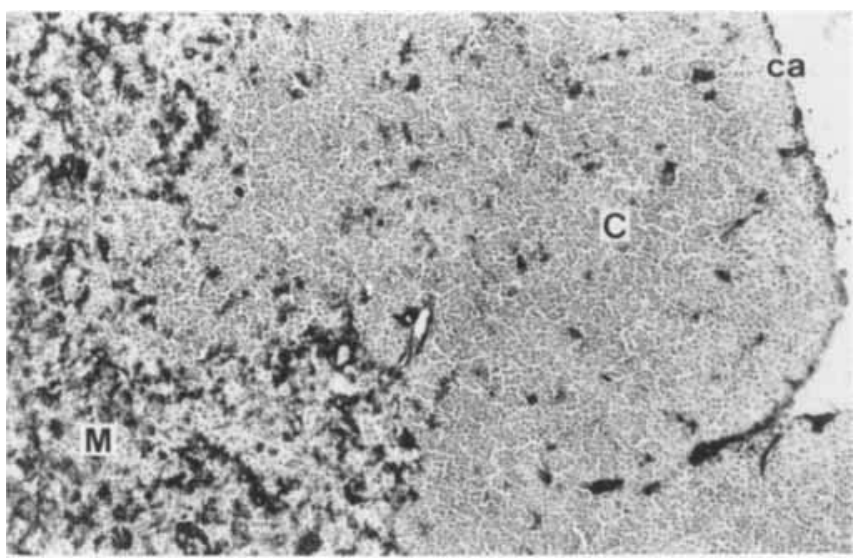

Figure 2. ER-BMDM1-positive $M \varnothing$ and IDC in the thymus. $\mathrm{ca}=$ capsule: $\mathrm{C}=$ cortex; $\mathrm{M}=$ medulla. Original magnification $\times 140$.

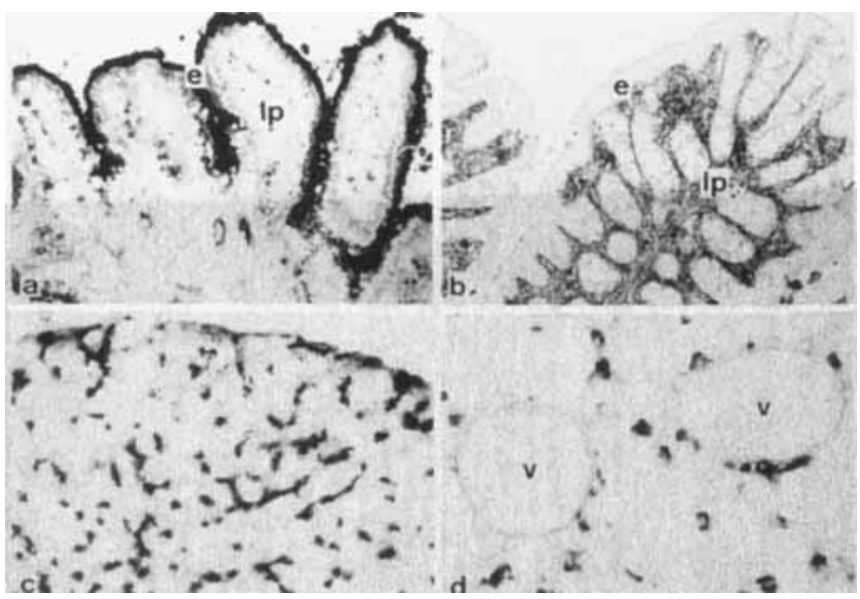

Figure 3. ER-BMDM1 reactivity on frozen sections of nonlymphoid organs. (a) small intestine: (b) large intestine; (c) liver; (d) lung: $\mathrm{e}=$ epithelium: Ip = lamina propria; $\mathrm{v}=$ venule. Original magnifications $\times 125$ (a.b) and $\times 310(\mathrm{c}, \mathrm{d})$.

isolated after 7 days strongly expressed the ER-BMDM1 Ag (Fig. 4B). Similarly, the MФ precursor cell line ROC2 [16] expressed little Ag. but induction of maturation simultaneously induced expression of the ER-BMDM1 Ag

4 Figure 1. ER-BMDM1 reactivity on frozen sections of spleen and mesenteric LN. For comparison, serial spleen sections (a-d) were stained with ER-BMDM1 (a), ER-TR9 (b; marginal zone M $\varnothing$ ). MOMA-1 (c: marginal metallophilic Mø), and RA3 6B2 (d; B-cells). ER-BMDM1 stains IDC and PALS Mø in the splenic white pulp and "marginal red pulp $M \phi$ " (indicated with the large arrow) in the red pulp (RP). The small arrow indicates the central arteriole: $P=$ periarteriolar lymphocyte sheath: $F=$ follicle. Serial LN seetions (e.f and g.h) were stained with ER-BMDM1 (c.g). RA3 6B2 (f: B cells) and ER-TR9 (h: medullary sinus M $\varnothing$ ). In the $L . N$ cortex. ER-BMDM1-positive Mø occur in the capsule (indicited with the arrow) and mainly outside the $B$ cell area $(O C=$ outer cortex). IDC are easily distinguished in the paracortex (PC). In the medulla. ER-BMDMI-positive Mø are associated mainly with the medullary cords and clearly distinct from the medullary sinus My detected by ER-TR\%. Asterisks in (g) and (h) indicate the same locations in serial sections. Original magnifications $\times 125(\mathrm{a}-\mathrm{d}), \times 95(\mathrm{c}, \mathrm{f})$ and $\times 245(\mathrm{~g}, \mathrm{~h})$.
(A)

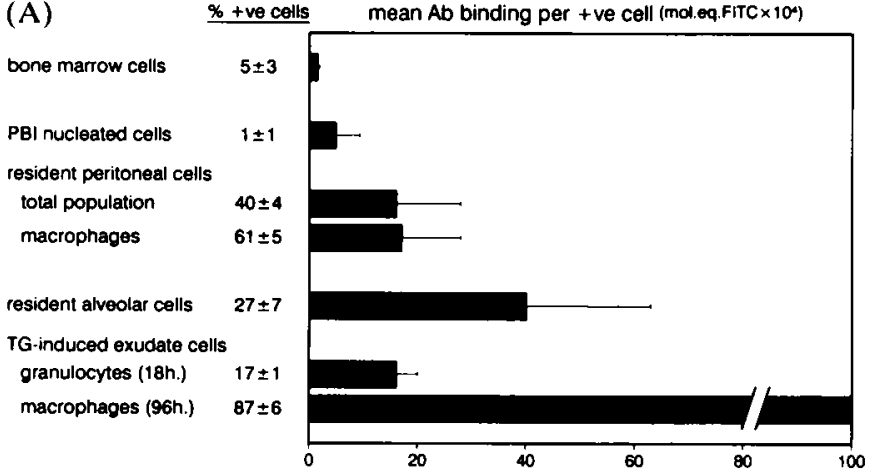

(B) cell type

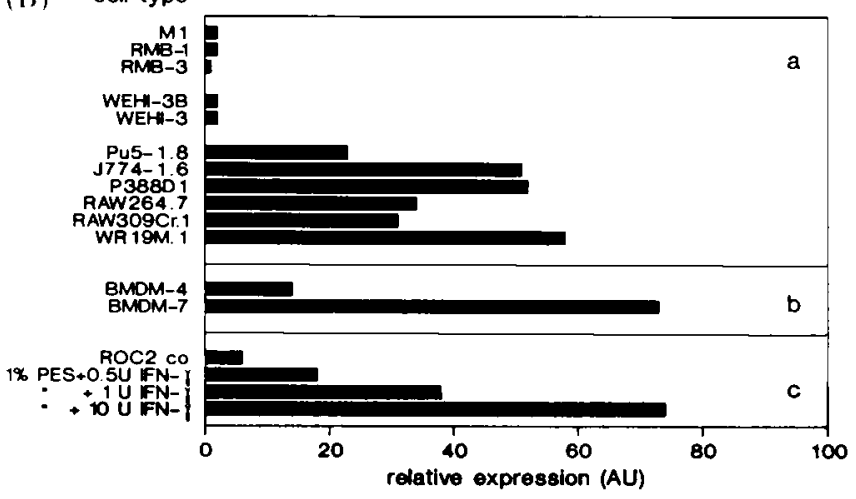

Figure 4. (A) ER-BMDM1 Ag expression by freshly isolated cell populations as determined by FCM. The percent of positive cells in these populations and the net $\mathrm{mAb}$ binding per positive cell represent the mean of at least three experiments \pm SD. mAb binding is expressed in soluble FITC molecular equivalents (mol.cq.FITC). $\mathrm{PBI}=$ peripheral blood; $\mathrm{TG}=$ thioglycollate. $(\mathrm{B})$ ER-BMDM 1 Ag expression during M $\varnothing$ maturation as determined using three maturation models. (a) A panel of $M \emptyset$ cell lines ordered in a linear differentiation sequence [17]: $M \varnothing$ precursor (M1, RMB-1, RMB-3), immature Mø (WEHI-3B,WEHI-3) and mature Mø cell lines (Pu5-1.8. J774-1.6, P388D1, RAW264.7. RAW309Cr.1.WR19M.1); (b) Immature nonadherent Mø precursor cells, isolated after 4 days of M-CSF stimulated BM culture (BMDM-4) are compared to mature adherent BM-derived $M \emptyset$, isolated after 7 days of culture (BMDM-7); (c) Induction of maturation in the M $\phi$ precursor hybrid R0C2 [16] by culture for 5 days with $1 \%$ post-LPS scrum (PES) supplemented with $0.5 \mathrm{U}$, $1 \mathrm{U}$ or $10 \mathrm{U}$ IFN $-\gamma / \mathrm{ml}$. The level of $\mathrm{mAb}$ binding is determined by ELISA and expressed in arbitrary units (AU), relative to an internal standard [16]. Data show one of three independent experiments with similar results.

(Fig. 4B). Taking these results together, we conclude that the ER-BMDM1 aminopeptidase is expressed increasingly beyond the monocytic stage in a strict maturation-related manner.

\section{Discussion}

The data presented in this report indicate that $\mathrm{mAb}$ ER-BMDM1 binds to an aminopeptidase at the cell surface of mouse $M \Phi, \mathrm{DC}$ and microvillous epithelia. Moreover, the ER-BMDM1 Ag is expressed in increasing amounts as MФ mature beyond the monocytic stage. Our finding that within the hemopoietic lineage - only DC/IDC and a MФ subpopulation express the ER-BMDM1 Ag, contributes to the evidence for a close phenotypic relationship between 
these cell types $[9,20,25]$. Recently published data indicate that a developmental relationship exists as well, since monocytes can be stimulated to differentiate into cells with morphological, phenotypical and functional features of DC $[26,27]$. In addition, stimuli which induce $M \Phi$ differentiation also induce development of DC from BM precursors $[28,29]$. The observation that BM-derived DC likely pass through the monocytic stage during their development [29] is in line with our finding that ER-BMDM1 Ag expression significantly increases after the monocytic stage. Hence, our data support the view that DC/IDC belong to the mononuclear phagocyte system, rather than constituting a separate cell lineage as suggested by others $[10,30]$.

The specific reactivity of ER-BMDM1 $\mathrm{mAb}$ with microvilli in non-lymphoid organs correlates with the demonstrated enzymatic activity of the recognized Ag. Most likely, the ER-BMDM1 Ag is identical to leucine aminopeptidase [31] and aminopeptidase $\mathrm{N}$ [32]. We base this identification on the similar linkage between $M \Phi$ maturation stage and expression of leucine aminopeptidase [33] as well as on the similarity in tissue distribution of aminopeptidase $\mathrm{N}$ and the ER-BMDM1 Ag [32]. Recently it was recognized that the human CD13 Ag exhibits aminopeptidase $\mathrm{N}$ activity $[34,35]$. The similarity in both molecular mass and enzyme activity suggests that the Ag recognized by ER-BMDM1 is the mouse homolog of human CD13. However, CD13 Ag is expressed by immature human myeloid cells and granulocytes [36], in contrast to the mouse ER-BMDM1 Ag. Additional studies are now in progress to investigate the putative homology between the ER-BMDM1 aminopeptidase and the CD13 Ag.

We wish to thank Jane Voerman, Anita Jansen and Matthijs Breel for their contributions to the work presented in this report, Arnold Reuser for advice on brush border enzymology, and Tar van Os for preparation of the figures. We gratefully acknowledge Priscilla Campbell for critical review of the manuscript.

Received October 17, 1991; in final revised form February 28, 1992.

\section{References}

1 Unanue, E. R. and Allen, P. M., Science 1987. 236: 551.

2 Gordon, S. Keshav, S. and Chung, L. P., Curr. Opin. Immunol. 1988. 1: 26.

3 Papadimitriou, J. M. and Ashman, R. B., Ultrastruct. Pathol. 1989. 13: 343.

4 Van Vliet, E., Melis, M. and Van Ewijk, W., J. Histochem. Cytochem. 1985. 33: 40.

5 Kraal, G. and Janse, M., Immunology 1986. 58: 665.
6 Austyn, J. M. and Gordon, S., Eur. J. Immunol. 1981. 11: 805.

7 Witmer, M. D. and Steinman, R. M., Am. J. Anat. 1984. 170 . 465.

8 Malorny, U., Michels, E. and Sorg, C., Cell. Tissue Res. 1986. 243: 421.

9 Kraal, G., Rep, M. and Janse, M., Scand. J. Immunol. 1987. 26: 653 .

10 Austyn, J. M., Immunology 1987. 62: 161.

11 Leenen, P. J. M., Melis, M., Slieker, W. A. T. and Van Ewijk, W., Eur. J. Immunol. 1990. 20: 27.

12 Pierres, A., Naquet, P., Van Agthoven, A., Bekkhoucha, F., Denizot, F., Mishal, Z., Schmitt-Verhulst, A.-M. and Pierres, M., J. Immunol. 1984. 132: 2775.

13 Ho, M.-K. and Springer, T. A., J. Immunol. 1982. 128: 1221.

14 Kraal, G., Breel, M., Janse, M. and Bruin, G., J. Exp. Med. 1986. 163: 981.

15 Coffman, R. L., Immunol. Rev. 1982. 69: 5.

16 Leenen, P. J. M., Slieker, W. A. T., Melis, M. and Van Ewijk, W., Eur. J. Immunol. 1990. 20: 15.

17 Leenen, P. J. M., Jansen, A. M. A. C. and Van Ewijk, W., Differentiation 1986. 32: 157.

18 Breel, M., Mebius, R. E. and Kraal, G., Eur. J. Immunol. 1987. 17: 1555.

19 Leenen, P. J. M., Kroos, M. J., Melis, M., Slieker, W. A. T., Van Ewijk, W. and Van Eijk, H. G., Exp. Cell. Res. 1990. 189: 55.

20 Breel, M., Van der Ende, M., Sminia, T. and Kraal, G., Immunology 1988. 63: 657.

21 De Jong, J. P., Voerman, J. S. A., Leenen, P. J. M., Van der Sluijs-Gelling, A. J. and Ploemacher, R. E., Histochem. J. 1991. 23: 392 .

22 Green, M. A., Sviland, L., Malcolm, A. J. and Pearson, A. D. J., J. Clin. Pathol. 1989. 42: 875.

23 Pont, S., Regnier-Vigouroux, A., Naquet, P., Blanc, D., Pierres, A., Marchetto, S. and Pierres, M., Eur. J. Immunol. 1985. 15: 1222.

24 Hume, D. A., Robinson, A. P., MacPherson, G. G. and Gordon, S., J. Exp. Med. 1983. 158: 1522.

25 Crowley, M., Inaba, K., Witmer-Pack, M. and Steinmann, R. M., Cell. Immunol. 1989. 118: 108.

26 Kabel, P. J., de Haan-Meulman, M., Voorbij, H. A. M., Kleingeld, M., Knol, E. F. and Drexhage, H. A., Immunobiology 1989. 179: 395.

27 Peters, J. H., Ruppert, J., Gieseler, R. K. H., Najar, H. M. and Xu, H., Pathobiology 1990. 59: 122.

28 Reid, C. D. L., Fryer, P. R., Clifford, C., Kirk, A., Tikerpae, J. and Knight, S. C., Blood 1990. 76: 1139.

29 Gieseler, R. K. H., Röber, R.-A., Kuhn, R., Weber, K., Osborn, M. and Peters, J. H., Eur. J. Cell Biol. 1991. 54: 171.

30 Steinman, R. M., Annu. Rev. Immunol. 1991. 9: 271.

31 Wachsmuth, E. D. and Wüst, B., Histochem. J. 1982. 14: 221.

32 Bowes, M. A. and Kenny, A. J., Immunology 1987. 60: 247.

33 Wachsmuth, E. D., Exp. Cell Res. 1975. 96: 409.

34 Look, A. T., Ashmun, R. A., Shapiro, L. H. and Peiper, S. C., J. Clin. Invest. 1989. 83: 1299.

35 Ashmun, R. A. and Look, A. T., Blood 1990. 75: 462.

36 Griffin, J. D., Ritz, J., Beveridge, R. P., Lipton, J. M., Daley, J. F. and Schlossman, S. F., Int. J. Cell Cloning 1983. 1: 33. 